\title{
Biodigestão anaeróbia de efluente de abatedouro avícola*
}

\author{
Arley Borges de Morais Oliveira ${ }^{*}$, Ana Carolina Amorim Orrico ${ }^{2}$, Marco Antonio Previdelli Orrico Júnior ${ }^{3}$, \\ Natalia da Silva Sunada ${ }^{4}$ Stanley Ribeiro Centurion ${ }^{5}$
}

\section{RESUMO}

Objetivou-se, com este trabalho, avaliar o processo de biodigestão anaeróbia no tratamento de efluentes de abatedouro avícola, considerando-se os TRH de 7, 14 e 21 dias, além da adição de enzima lipolítica aos substratos, nas concentrações de $0 ; 0,5 ; 1,0$ e 1,5 $\mathrm{g} \mathrm{L}^{-1}$ de carga adicionada aos biodigestores. A influência dos TRH e da adição de enzima lipolítica aos substratos foi avaliada por meio das produções de biogás e $\mathrm{CH}_{4}$, dos potenciais de produção por DQO, adicionada e removida, bem como pelas reduções dos teores de DQO, concentrações de $\mathrm{N}$, P e K e dos valores de $\mathrm{pH}$. Os resultados obtidos demonstraram que houve influência dos TRH (em que o TRH 7 expressou os melhores resultados, para produção semanal média de biogás, com 40,7 L, e $\mathrm{CH}_{4}, \operatorname{com} 32,2 \mathrm{~L}$ ) e das concentrações de enzimas, com maiores valores de produção para os tratamentos 1,0 (24,6 L) e 1,5 $\mathrm{g} \mathrm{L}^{-1}(26,2 \mathrm{~L})$, que não diferiram entre si. As

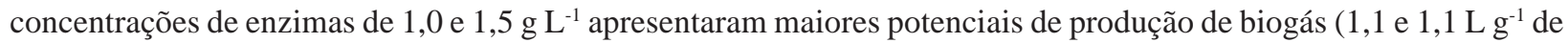
DQO adicionada, respectivamente) e metano ( 0,9 e $0,8 \mathrm{~L} \mathrm{~g}^{1}$ de DQO adicionada, respectivamente), quando comparadas com as da $0,5 \mathrm{~g} \mathrm{~L}^{-1}\left(0,8\right.$ e $0,7 \mathrm{~L} \mathrm{~g}^{-1}$ biogás e $\mathrm{CH}_{4}$, respectivamente) e $0\left(0,7\right.$ e $0,5 \mathrm{~L} \mathrm{~g}^{-1}$ biogás e $\mathrm{CH}_{4}$, respectivamente). As maiores remoções de DQO foram alcançadas nas concentrações de $0,5 \mathrm{~g} \mathrm{~L}^{-1}(83,3 \%)$ e TRH de 21 dias (74,4\%). Contudo, para que haja maior eficiência na reciclagem energética, recomenda-se a utilização de concentrações de $1,0 \mathrm{~g} \mathrm{~L}^{-1} \mathrm{de}$ efluente e tempo de retenção hidráulica de 7 dias.

Palavras-chave: Biofertilizante, demanda química de oxigênio, efluente de abatedouro avícola, metano.

\begin{abstract}
\section{Anaerobic digestion of broiler slaughterhouse wastewater}

The objective of this study was to evaluate the process of anaerobic digestion treatment of poultry slaughterhouse wastewater, considering hydraulic retention time (HRT) of 7, 14 and 21 days, plus the addition of lipolytic enzyme to the substrates at concentrations of $0 ; 0.5 ; 1.0$ and $1.5 \mathrm{~g} \mathrm{~L}^{-1}$ charge added to the digesters. The influence of HRT and the addition of lipolytic enzyme to the substrates was evaluated by biogas production and $\mathrm{CH}_{4}$ production potentials for COD (chemical oxygen demand) added and removed as well as by reductions in the levels of COD, concentrations of $\mathrm{N}, \mathrm{P}$ and $\mathrm{K}$ and $\mathrm{pH}$ values. The results showed that there was influence of HRT (HRT 7 in which the expressed best results, average weekly production of biogas with $40.7 \mathrm{~L}^{-1}$ and $32.2 \mathrm{~L}^{-1} \mathrm{CH}_{4}$ ) and concentrations of enzymes with higher production values to treatments $1.0(24.6 \mathrm{~L})$ and $1.5 \mathrm{~g} \mathrm{~L}^{-1}(26.2 \mathrm{~L})$, which did not differ. The enzyme concentrations of
\end{abstract}

Recebido para publicação em 18/08/2011 e aprovado em 10/10/2011

${ }^{1}$ Zootecnista, Mestre. Departamento de Ciências Agrárias da Universidade Federal da Grande Dourados, Rodovia Dourados, Itahum, Km 12, 79804-970, Dourados, Mato Grosso do Sul, Brasil. arleydeoliveira@ hotmail.com

${ }^{2}$ Zootecnista, Doutora. Departamento de Ciências Agrárias da Universidade Federal da Grande Dourados, Rodovia Dourados, Itahum, Km 12, 79804-970, Dourados, Mato Grosso do Sul, Brasil. anacarolamorim@ @otmail.com

${ }^{3}$ Zootecnista, Doutor. Departamento de engenharia Agrícola da Universidade Estadual Paulista, Avenida Prof. Paulo Donato Castellane, s/nº, Campos Jaboticabal, 14884-900, Jaboticabal, São Paulo, Brasil. marcoorrico@yahoo.com.br

${ }^{4}$ Médica Veterinária, Mestre. Departamento de Ciências Agrárias da Universidade Federal da Grande Dourados, Rodovia Dourados, Itahum, Km 12, 79804-970, Dourados, Mato Grosso do Sul, Brasil. natysunada@ hotmail.com

${ }^{5}$ Zootecnista. Departamento de Ciências Agrárias da Universidade Federal da Grande Dourados, Rodovia Dourados, Itahum, Km 12, 79804-970, Dourados, Mato Grosso do Sul, Brasil..stanley_kb@hotmail.com

*Trabalho extraído de Dissertação de Mestrado.

Rev. Ceres, Viçosa, v. 58, n.6, p. 690-700, nov/dez, 2011 
1.0 and $1.5 \mathrm{~g} \mathrm{~L}^{-1}$ showed the largest potential for biogas production (1.1 and $1.1 \mathrm{~g} \mathrm{~L}^{-1}$ of COD added, respectively) and methane (0.9 and $0.8 \mathrm{~g} 1 \mathrm{~L}$ COD added, respectively), compared with $0.5 \mathrm{~g} \mathrm{~L}^{-1}\left(0.8\right.$ and $0.7 \mathrm{~g} \mathrm{~L}^{-1}$ biogas and $\mathrm{CH}_{4}$ respectively) and $0 \mathrm{~g} \mathrm{~L}^{-1}\left(0.7\right.$ and $0.5 \mathrm{~g} \mathrm{~L}^{-1}$ biogas and $\mathrm{CH} 4$, respectively). The highest $\mathrm{COD}$ removals were achieved at concentrations of $0.5 \mathrm{~g} \mathrm{~L}^{-1}(83.3 \%)$ and HRT of 21 days $(74.4 \%)$. However for there to be a more efficient energy recycling, it is recommended to use concentrations of $1.0 \mathrm{~g} \mathrm{~L}^{-1}$ effluent and hydraulic retention time of seven days.

Key words: Bio-fertilizer, chemical oxygen demand, broiler slaughterhouse effluent, methane.

\section{INTRODUÇÃO}

A produção brasileira de frangos de corte desenvolve-se de maneira satisfatória. No ano de 2010, a atividade obteve aumento de $11,4 \%$ em relação a 2009 (10,980 milhões), chegando a 12,2 milhões de toneladas. A região centro-oeste contribuiu com $13,7 \%$ dos animais abatidos e com 14,6\% das exportações. Para o ano de 2011, a estimativa é que esse crescimento seja de $5,9 \%$, o que levaria a uma produção média de 12,9 milhões (UBA, 2011). Todo esse quadro tem elevado a produção de resíduos pelas indústrias de abate e processamento de frangos de corte (Salminen \& Rintala, 2002; Alvarez \& Lidén, 2008).

O efluente de abatedouro avícola apresenta grande poder poluente, por conter em sua composição principalmente gorduras, sangue, conteúdo visceral e pequenos pedaços de carcaças (Beux, 2005; Rigo, 2004; Salminen \& Rintala, 2002; Alvarez \& Lidén, 2008; Chen et al., 2008). Como alternativa, visando à redução do impacto ambiental e à recuperação de energia e nutrientes contidos no efluente de abatedouros avícolas, a biodigestão anaeróbia demonstra ser um eficiente sistema de tratamento e reciclagem, uma vez que os nutrientes contidos no efluente garantem a sobrevivência e reprodução dos micro-organismos presentes durante o processo, permitindo que ocorra a degradação da fração orgânica não estável e, portanto, poluente, até a forma estável.

No entanto, pela presença de grandes quantidades de óleos e gorduras nesse resíduo, a degradação do material muitas vezes torna-se lenta e até ineficiente (Rigo et al., 2008; Gannoun et al., 2009; Valladão et al., 2009; Johns, 1995; Camarota et al., 2001). Desta forma, o uso de enzimas lipolíticas em efluentes de abatedouros mostra-se uma alternativa promissora (Leal et al., 2006; Valladão et al., 2007), uma vez que as enzimas auxiliam na conversão de óleos e gorduras em produtos menos complexos (biogás composto por $\mathrm{CH}_{4}$ e $\mathrm{CO}_{2}$, principalmente), ajudando na degradação do material pelos micro-organismos.

A produção de biogás, obtida por biodigestão anaeróbia de efluente de abatedouro de aves, com crescentes níveis de inclusão de lipase, foi estudada por Valladão et al. (2007).
Nesta mesma condição, os autores observaram que a produção de biogás saltou de 37 para $175 \mathrm{~mL}$, em quatro dias de avaliação, quando se promoveu a adição de $0,1 \mathrm{~g} \mathrm{~L}^{-1}$, em comparação com a carga sem adição de enzima. Avaliando lipases de duas diferentes fontes comerciais, Dors (2006) obteve um volume médio de produção de metano de 1.252 e $1.138 \mathrm{~mL}$, em biodigestores com volume total de $300 \mathrm{~mL}$, avaliados durante 34 dias.

Objetivou-se, neste trabalho, avaliar os benefícios do uso de diferentes doses de enzimas lipolíticas $(0 ; 0,5 ; 1,0$ e $1,5 \mathrm{~g} \mathrm{~L}^{-1}$ do volume de carga diária) e tempos de retenção hidráulica (7, 14 e 21 dias) sobre a produção de biogás e a redução do poder poluente do efluente de abatedouro avícola.

\section{MATERIAL E MÉTODOS}

O experimento foi conduzido na Universidade Federal da Grande Dourados, na Faculdade de Ciências Agrárias, no Laboratório de Aproveitamento dos Dejetos Gerados na Produção Animal, a partir do primeiro trimestre de 2010.

Para execução do experimento, foi utilizado efluente de abatedouro de aves, com a adição de doses crescentes (0, 0,5, 1,0 e 1,5 $\mathrm{g} \mathrm{L}^{-1}$ do volume de carga diária) de enzimas lipolíticas (Pancreatina NF de origem animal, com perda por dessecação de não mais que $5,0 \%\left(160{ }^{\circ} \mathrm{C} / 4\right.$ horas $)$, lipídios (não mais que 3,0\%, com atividade de 9,8U USP/ $\mathrm{mg}$, produzida pela indústria Vetec química china LTDA, sendo estas informações disponibilizadas pelo fabricante), como substrato para o abastecimento de biodigestores semicontínuos, manejados por 7, 14 e 21 dias de retenção hidráulica.

Para tanto, foi realizado um ensaio prévio de caracterização no efluente produzido pelos diversos setores do abatedouro, sendo possível desta forma verificar a composição e o poder poluente desses resíduos (Tabela 1). Foram determinados no efluente: teores de Sólidos totais (ST), Sólidos voláteis (SV), pH, demanda química de oxigênio (DQO), números mais prováveis de coliformes totais e termotolerantes e quantidades de N, P e K presentes nas amostras. 
Os biodigestores semicontínuos constituíam-se de duas partes distintas: o recipiente com o material em fermentação e o gasômetro. O recipiente com o material em fermentação era composto por um cilindro reto de PVC com diâmetro de $250 \mathrm{~mm}$ e com $1 \mathrm{~m}$ de comprimento, tendo as extremidades fixadas com duas placas de PVC, com 1,5 $\mathrm{cm}$ de espessura de cada lado. Em uma placa, foi fixado o cano de entrada, por onde foi realizado o abastecimento; na outra extremidade, foram fixados dois canos, um, destinado à saída do biofertilizante e, outro, à saída do biogás. Os detalhes do biodigestor podem ser visualizados na Figura 1.

O gasômetro foi constituído de dois cilindros de 250 e $300 \mathrm{~mm}$ de diâmetro, inseridos, um no outro, de tal forma que o espaço existente entre a parede externa do cilindro interior e a parede interna do cilindro exterior comportasse um volume de água ("selo de água"), atingindo profundidade de $500 \mathrm{~mm}$. O cilindro de $300 \mathrm{~mm}$ de diâmetro foi fixado sobre uma placa de PVC com $2,5 \mathrm{~cm}$ de espessura, recebendo o cilindro de $250 \mathrm{~mm}$ de diâmetro no seu interior. O cilindro de $250 \mathrm{~mm}$ de diâmetro teve uma das extremidades vedada com um cap que recebeu o biogás produzido, a outra extremidade foi emborcada no selo de água para armazenar o biogás produzido. Os gasômetros foram dispostos sobre uma bancada, em condições de temperatura ambiente, abrigados da luz solar e chuvas. Os detalhes do gasômetro poderão ser visualizados na Figura 2.

Tabela 1. Caracterização do efluente de abatedouro avícola

\begin{tabular}{lcc}
\hline Componente & & Concentração \\
\hline Sólidos totais (ST) & $\mathrm{mg} \mathrm{L}^{-1}$ & $1.500,0$ \\
Sólidos voláteis (SV) & $\mathrm{mg} \mathrm{L}^{-1}$ & $1.290,0$ \\
$\mathrm{pH}$ & - & 6,9 \\
Coliformes totais & $\mathrm{mg} \mathrm{L}^{-1}$ & $2,40 \mathrm{E}+10$ \\
Coliformes termotolerantes & $\mathrm{mg} \mathrm{L}^{-1}$ & $7,70 \mathrm{E}+09$ \\
N amoniacal & $\mathrm{mg} \mathrm{L}^{-1}$ & 86,8 \\
P total & $\mathrm{mg} \mathrm{L}^{-1}$ & 3,5 \\
K & $\mathrm{mg} \mathrm{L}^{-1}$ & 58,0 \\
DQO & $\mathrm{mg} \mathrm{L}^{-1}$ & $2.490,1$ \\
\hline
\end{tabular}

Antes do início do período experimental, foi efetuada a produção do inóculo, de acordo com Orrico Júnior et al. (2010), objetivando a adaptação mais rápida da biomassa ao substrato, acelerando-se, assim, as produções de biogás. O inóculo foi produzido em biodigestores batelada de bancada, utilizando-se uma mistura de dejetos de bovino e efluente de abatedouro avícola, na proporção de 40:60, respectivamente. O efluente desses biodigestores foi considerado inóculo no momento em que os biodigestores mostraram-se estabilizados (quando a produção de biogás atingiu pico máximo). Iniciou-se a próxima fase do trabalho, na qual o inóculo fez parte de $15 \%$ da massa seca adicionada aos biodigestores ((volume total do biodigestor x concentração de ST do efluente) x 0,15).

O substrato, gerado durante os processos de abate e processamento das carcaças, para o abastecimento dos biodigestores semicontínuos foi coletado, a cada 10 dias, em abatedouro industrial, localizado no município de Dourados - MS, sendo o material coletado, congelado a uma temperatura de aproximadamente $-20^{\circ} \mathrm{C}$, e descongelado de acordo com a necessidade diária dos biodigestores.

Os biodigestores receberam cargas diárias e o volume de carga foi determinado segundo o tempo de retenção adotado, ou seja, considerando-se que a capacidade média dos biodigestores era de 26,6 litros e os períodos de retenção de 7, 14 e 21 dias, a carga diária efetuada foi de $3,7,1,9$ e $1,3 \mathrm{~L} \mathrm{~d}^{-1}$ de substrato, respectivamente. Desta forma, foram abastecidos com uma carga orgânica de 9.213,4, 4.312,2 e 3.237,1 $\mathrm{mg} \mathrm{d}^{1}$ de DQO, respectivamente. Os biodigestores foram monitorados durante seis semanas após o período de adaptação de dez dias, considerando-se cada condição de operação (doses de enzima lipolítica e diferentes tempos de retenção).

Os valores de SV e ST foram determinados diariamente (pelo método gravimétrico), de acordo com APHA et al. (1995). As coletas de amostras, para a realização da contagem dos números mais prováveis de coliformes totais e termotolerantes, foram realizadas semanalmente e analisadas por meio da técnica de tubos múltiplos, bem como, para a análise de DQO, por refluxo fechado, realizadas de acordo com metodologia proposta pela APHA et al. (1995).

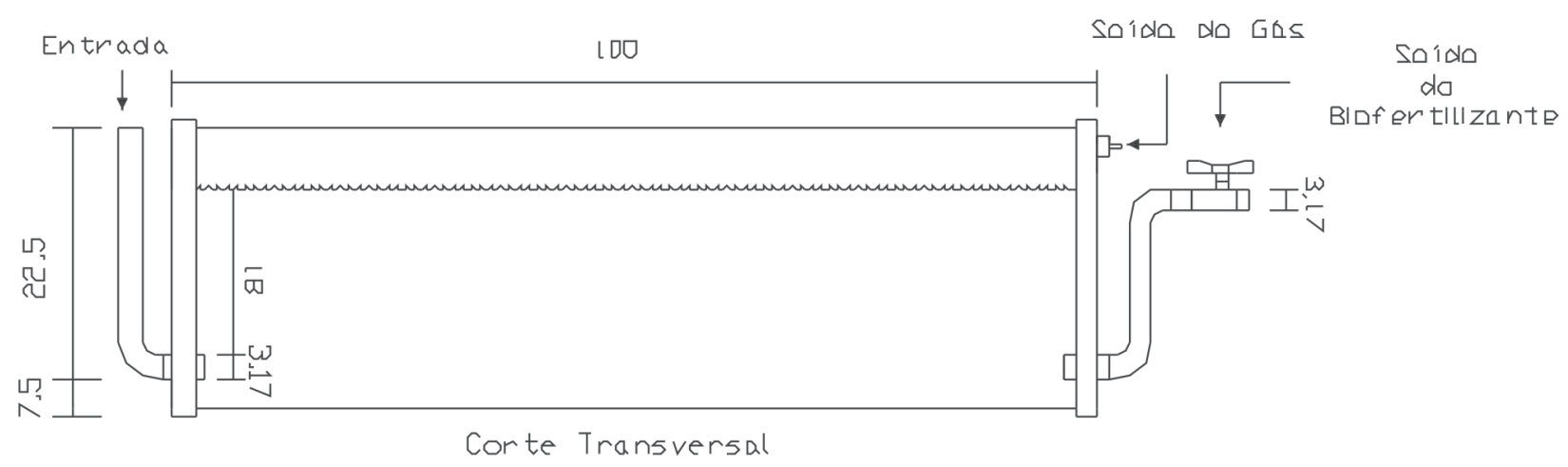

Figura 1. Corte transversal dos biodigestores tubulares que foram utilizados no experimento.

Rev. Ceres, Viçosa, v. 58, n.6, p. 690-700, nov/dez, 2011 
Para as determinações de N, P e K nas amostras coletadas no afluente e no efluente, foi realizada uma secagem das amostras em estufa de circulação forçada de ar, a $60{ }^{\circ} \mathrm{C}$, por 48 horas. Após a secagem, as amostras foram submetidas à digestão da matéria orgânica. Para tanto, foi utilizado o digestor Digesdahl Hach, que promoveu a digestão total da matéria orgânica com ácido sulfúrico $\left(\mathrm{H}_{2} \mathrm{SO}_{4}\right)$ e peróxido de hidrogênio $\left(\mathrm{H}_{2} \mathrm{O}_{2}\right)$, em concentração de $50 \%$. Com o extrato obtido da digestão sulfúrica, foi possível a determinação dos teores de N, Pe K, segundo Bataglia et al. (1983). O teor de nitrogênio amoniacal foi determinado conforme metodologia descrita por Silva (1981). Os teores de fósforo total e potássio foram determinados pelo método colorimétrico, conforme Malavolta (1989), utilizando-se espectrofotômetro.

Os valores de $\mathrm{pH}$ foram acompanhados semanalmente por meio de um peagâmetro de bancada, de acordo com metodologia descrita pela APHA et al. (1995).

As produções de biogás foram observadas diariamente e a sua qualidade, teores de metano, avaliada semanalmente. Os volumes de biogás produzidos diariamente foram determinados, medindo-se o deslocamento vertical dos gasômetros e multiplicando-se por sua área da seção transversal interna. Após cada leitura, os gasômetros foram zerados, utilizando-se o registro de descarga do biogás. A correção do volume de biogás para as condições de 1 atm e $20{ }^{\circ} \mathrm{C}$ foi calculada, utilizando-se a metodologia descrita por Caetano (1985). Já as análises para a obtenção da composição do biogás produzido foram realizadas semanalmente, em cromatógrafo de fase gasosa Finigan GC-2001, equipado com as colunas Porapack Q e Peneira Molecular e detector de conduti- vidade térmica, visando principalmente à determinação dos teores de $\mathrm{CH}_{4}$ e $\mathrm{CO}_{2}$.

A influência, sobre o processo de biodigestão anaeróbia, dos TRH (7, 14 e 21) e da adição de enzima lipolítica (nas concentrações de 0, 0,5, 1,0 e 1,5 $\mathrm{g} \mathrm{L}^{-1}$ ) aos substratos, foi avaliada por meio das produções e potenciais de produção de biogás e metano, bem como pela redução nos teores de DQO. Os potenciais de produção de biogás e metano foram calculados, utilizando-se os dados de produção diária de biogás e metano, em função das quantidades de DQO adicionadas e reduzidas durante o processo de biodigestão anaeróbia.

O delineamento utilizado foi o inteiramente casualizado, com parcela subdividida no tempo, sendo que cada repetição foi composta pelos dados médios das semanas após a estabilização dos biodigestores, ou seja, a primeira repetição contemplou os dados médios da primeira semana e, assim, sucessivamente, até a sexta semana. O efeito do período foi corrigido pelo delineamento, de forma que permitisse ser observada a interferência das enzimas e do TRH nos resultados. Para analisar os dados, foi utilizado o software (Sistema de Análise Estatística e Genética) (2000). Realizou-se análise de variância e as médias dos tratamentos foram comparadas por meio do teste de ScottKnott, a 5\% de significância.

\section{RESULTADOS E DISCUSSÃO}

As reduções nos teores de DQO em função das concentrações de enzimas adicionadas, após a biodigestão anaeróbia de efluentes de abatedouro avícola, encontradas no experimento, são apresentadas na Tabela 2 .
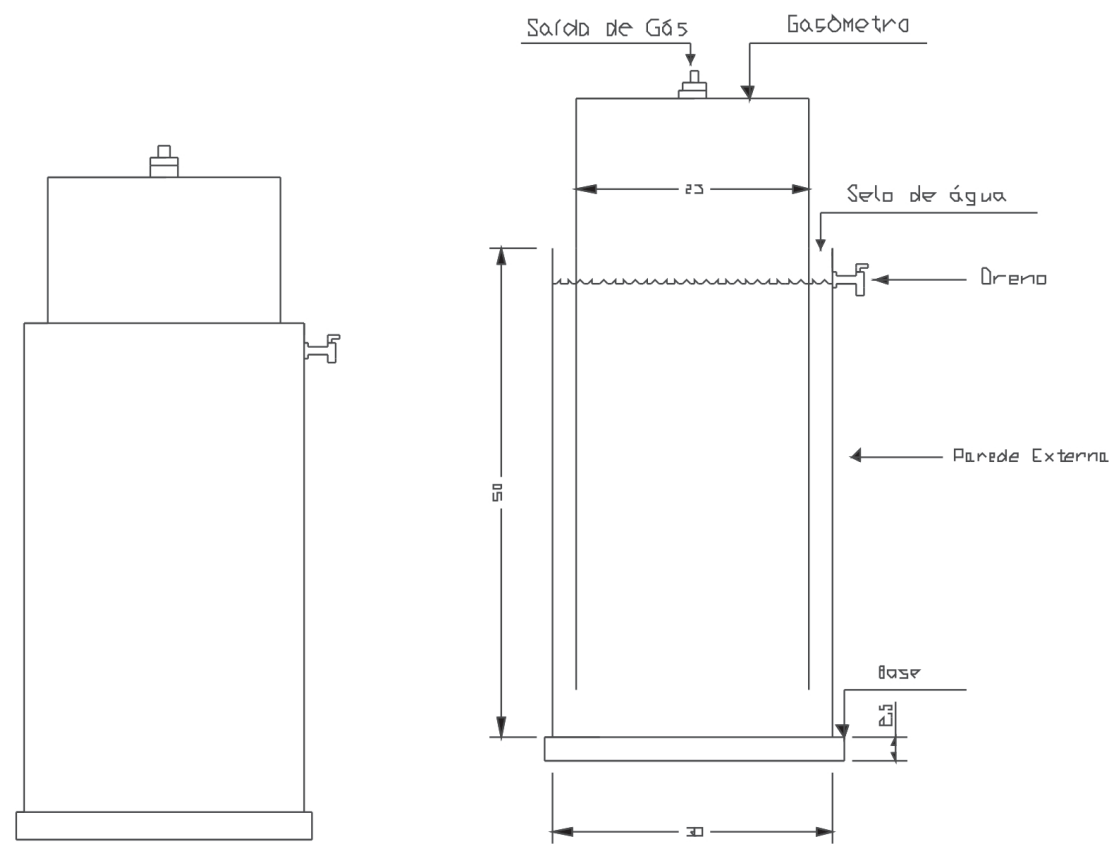

Figura 2. Desenho dos gasômetros que foram utilizados no experimento. 
$\mathrm{O}$ uso de diferentes doses de lipase influenciou $(\mathrm{P}<0,05)$ os valores de remoção de $\mathrm{DQO}$, sendo que o melhor resultado foi encontrado quando se utilizou a concentração de $0,5 \mathrm{~g} \mathrm{~L}^{-1}(82,3 \%)$. Os valores encontrados neste experimento foram semelhantes aos obtidos por Dors (2006) e Valladão et al. (2007), sendo eles 81 e 85\% respectivamente.

Ao observar os resultados apresentados na Tabela 2, nota-se que o uso de $0,5 \mathrm{~g} \mathrm{~L}^{-1}$ de lipase contribuiu com um aumento na remoção de DQO de $67 \%$, em comparação com o da não utilização da lipase. Esses resultados estão de acordo com os relatos feitos por Rosa et al. (2009) e Mendes et al. (2005), em que a realização da pré-hidrólise em efluentes de abatedouro auxilia na etapa inicial de degradação, aumentando consideravelmente a eficiência de remoção de material orgânico, durante o processo de biodigestão. Porém, na medida em que se aumentaram os níveis de inclusão, proporcionou-se um decréscimo na remoção de DQO. Isso pode ter ocorrido, provavelmente, em função de um aumento na concentração de glicerol e Ácidos Graxos de Cadeia longa (AGCL), principais produtos da hidrólise de moléculas de lipídios. O acúmulo de AGCL leva principalmente à limitação da atividade de bactérias fermentativas, por meio da redução do acesso aos substratos. Essa redução leva a um decréscimo na quantidade de $\mathrm{H}_{2}$, o que causa uma redução da atividade de algumas bactérias acetogênicas e metanogênicas, responsáveis pela degradação dos Ácidos Graxos Voláteis (AGV) com três ou mais carbonos e alcoóis, subprodutos da degradação dos AGCL, convertidos, por bactérias acetogênicas, a $\mathrm{CH}_{4}$ e $\mathrm{CO}_{2}$ principalmente.

Valladão (2005), ao realizarem a biodigestão anaeróbia de efluentes de abatedouro avícola, com 0,1, 0,5 e 1,0\% do peso/volume e sem hidrólise enzimática, observaram comportamento semelhante ao encontrado neste trabalho, uma vez que, ao submeter à biodigestão anaeróbia o efluente pré- hidrolisado com $0,1 \%$, a eficiência de remoção de DQO variou de 64 a 73\%. Já, quando foram usados maiores quantidades de enzima ( 0,5 e 1,0\%), a eficiência na remoção de $\mathrm{DQO}$ foi menor, em relação à da menor quantidade utilizada, mantendo-se eficiências de 40 e $20 \%$, respectivamente, o que indica que a atividade microbiana pode ser inibida com maiores níveis de enzima.

As produções e os potenciais de produção de biogás, bem como as concentrações de metano encontrados no experimento, para as diferentes quantidades de enzimas utilizadas são apresentados na Tabela 2.

Os resultados encontrados neste experimento demonstram que houve influência $(\mathrm{P}<0,05)$ das concentrações de enzimas sobre os potenciais de produção de biogás e metano, por DQO adicionada e reduzida. Dentre as concentrações de enzima empregadas, a quantidade de $0,5 \mathrm{~g}$ $\mathrm{L}^{-1}$ foi a que obteve menor potencial de produção de biogás e metano por $\mathrm{DQO}$ adicionada $(\mathrm{P}<0,05)$, quando comparados com o das concentrações de 1,0 e $1,5 \mathrm{~g} \mathrm{~L}^{-1}$ que não diferiram entre si (Figura 3).

Os resultados obtidos indicam que, quando se tem como principal objetivo o aumento nos potenciais de produção em função da DQO adicionada, é necessária à utilização de uma concentração de enzima superior a $0,5 \mathrm{~g} \mathrm{~L}^{-1}$. Esses valores também indicam que a adição de $1,5 \mathrm{~g} \mathrm{~L}^{-1} \mathrm{de}$ lipase não contribui para incremento na produção alcançada pela concentração anterior $\left(1,0 \mathrm{~g} \mathrm{~L}^{-1}\right)$. Se forem comparados com os resultados do tratamento testemunha, houve um aumento na produção de 59,2, 73,7 e 57,5\% para os potenciais de biogás e metano por DQO adicionada para as concentrações de $0,5,1,0$ e $1,5 \mathrm{~g} \mathrm{~L}^{-1}$, respectivamente, tornando inviável o uso de maior dose de enzima.

O comportamento obtido neste estudo indica que o uso de concentrações acima de $1,0 \mathrm{~g} \mathrm{~L}^{-1}$ pode ter causado um acúmulo de ácidos graxos de cadeia longa, o que levou a uma estabilização na síntese de $\mathrm{CH}_{4}$ e $\mathrm{CO}_{2}$ (principais gases componentes do biogás) e, consequentemente, nos potenciais de produção.

Tabela 2. Produções semanais de biogás e metano $\left(\mathrm{L}^{-1}\right)$, teores de metano na composição, potenciais de produção de biogás e metano por $\mathrm{g}^{-1}$ de DQO adicionada (DQOa) e removida (DQOr) e \% de remoção de DQO (RDQO), durante a biodigestão de efluente de abatedouro avícola em função dos níveis de enzimas usados

\begin{tabular}{|c|c|c|c|c|c|}
\hline \multirow{2}{*}{ Variáveis } & \multicolumn{5}{|c|}{ Níveis de Enzimas $\left(\mathrm{g} \mathrm{L}^{-1}\right)$} \\
\hline & $\mathbf{0}$ & 0,5 & 1,0 & 1,5 & $\mathrm{CV}(\%)$ \\
\hline RDQO $(\%)$ & $49,3 \mathrm{~d}$ & $82,3 a$ & $79,3 b$ & $68,6 c$ & 4,2 \\
\hline Biogás/DQOa $\left(\mathrm{L} \mathrm{g}^{-1}\right)$ & $0,7 \mathrm{~b}$ & $0,8 b$ & $1,1 \mathrm{a}$ & 1,1a & 37,7 \\
\hline Biogás/DQOr $\left(\mathrm{L} \mathrm{g}^{-1}\right)$ & $0,7 \mathrm{~b}$ & $1,3 a$ & $1,4 \mathrm{a}$ & $1,5 \mathrm{a}$ & 52,1 \\
\hline $\mathrm{CH}_{4} / \mathrm{DQOa}\left(\mathrm{L} \mathrm{g}^{-1}\right)$ & $0,5 b$ & $0,7 \mathrm{~b}$ & $0,9 \mathrm{a}$ & $0,8 \mathrm{a}$ & 35,0 \\
\hline $\mathrm{CH}_{4} / \mathrm{DQOr}\left(\mathrm{L} \mathrm{g}^{-1}\right)$ & $0,4 \mathrm{~b}$ & $1,0 \mathrm{a}$ & $1,0 \mathrm{a}$ & $1,1 \mathrm{a}$ & 52,5 \\
\hline Biogás $\left(\mathrm{L}^{-1}\right)$ & $22,3 b$ & $20,9 b$ & $24,6 \mathrm{a}$ & $26,2 \mathrm{a}$ & 23,3 \\
\hline Metano (\%) & $72,6 b$ & $78,8 \mathrm{a}$ & $78,9 \mathrm{a}$ & $79,5 \mathrm{a}$ & 3,8 \\
\hline Metano $\left(\mathrm{L}^{-1}\right)$ & $16,2 b$ & $16,5 b$ & $19,4 \mathrm{a}$ & $20,8 \mathrm{a}$ & 12,1 \\
\hline
\end{tabular}

$\mathrm{Na}$ linha, letras minúsculas comparam resultados obtidos nos níveis de adição de enzima. Médias seguidas de letras distintas diferem entre si, pelo teste de Scott-Knott $(\mathrm{P}<0,05)$. 
Cirne et al. (2007) observaram comportamento semelhante ao encontrado neste estudo, ao avaliarem a influência da concentração de lipídios na hidrólise e na biometanização de resíduos ricos em lipídios, submetidos a diferentes concentrações enzimáticas. Os autores concluíram que a adição de lipase aumentou a hidrólise de lipídios e a produção de metano; no entanto, as vantagens da adição de enzimas sobre os processos de degradação lipídica são minimizadas, na medida em que se elevam os níveis de enzima, mesmo quando os efluentes apresentam altas concentrações de lipídios. De acordo com os autores, isso ocorre por causa do acúmulo de ácidos graxos de cadeia longa, o que os torna o principal fator na inibição da degradação de lipídios e da produção de metano e biogás.

Os potenciais de produção de biogás e metano por DQO removida, encontrados neste experimento, foram influenciados $(\mathrm{P}<0,05)$ pelas quantidades de enzima utilizadas; no entanto não houve diferença significativa entre os tratamentos em que se utilizou a adição de lipase $\left(0,51,0\right.$ e $\left.1,5 \mathrm{~g} \mathrm{~L}^{-1}\right)$. Os valores encontrados neste experimento foram semelhantes aos (valores médios entre 1,4 e 1,6 $\mathrm{L} \mathrm{g}^{-1}$ de DQO removida) obtidos por Valladão et al. (2007), ao realizarem a biodigestão anaeróbia de efluente de abatedouro avícola, com doses crescentes de lipase.

Os resultados obtidos neste experimento para os potenciais de produção de biogás e metano por DQO removida demonstram que a provável inibição por ácidos graxos de cadeia longa pode ter advindo já na concentração de 0,5 $\mathrm{g} \mathrm{L}^{-1}$, tornando, assim, desnecessário o uso de concentrações acima desta.

As produções de biogás e metano apresentaram maiores valores para os tratamentos 1,0 e $1,5 \mathrm{~g} \mathrm{~L}^{-1}$, que não diferiram entre si (Tabela 2). O tratamento com $0,5 \mathrm{~g} \mathrm{~L}^{-1}$ não contribuiu para o aumento da produção de biogás e metano, apresentando comportamento semelhante ao do tratamento testemunha. Esse comportamento reforça a hipótese de estabilização na síntese de $\mathrm{CH}_{4}$ e $\mathrm{CO}_{2}$ por causa do acúmulo de AGCL. Desta forma, para que haja um incremento na produção de biogás e metano, faz-se necessário o uso das recomendações anteriores, ou seja, a concentração ideal não deve ultrapassar o nível de $1,0 \mathrm{~g} \mathrm{~L}^{-1}$.
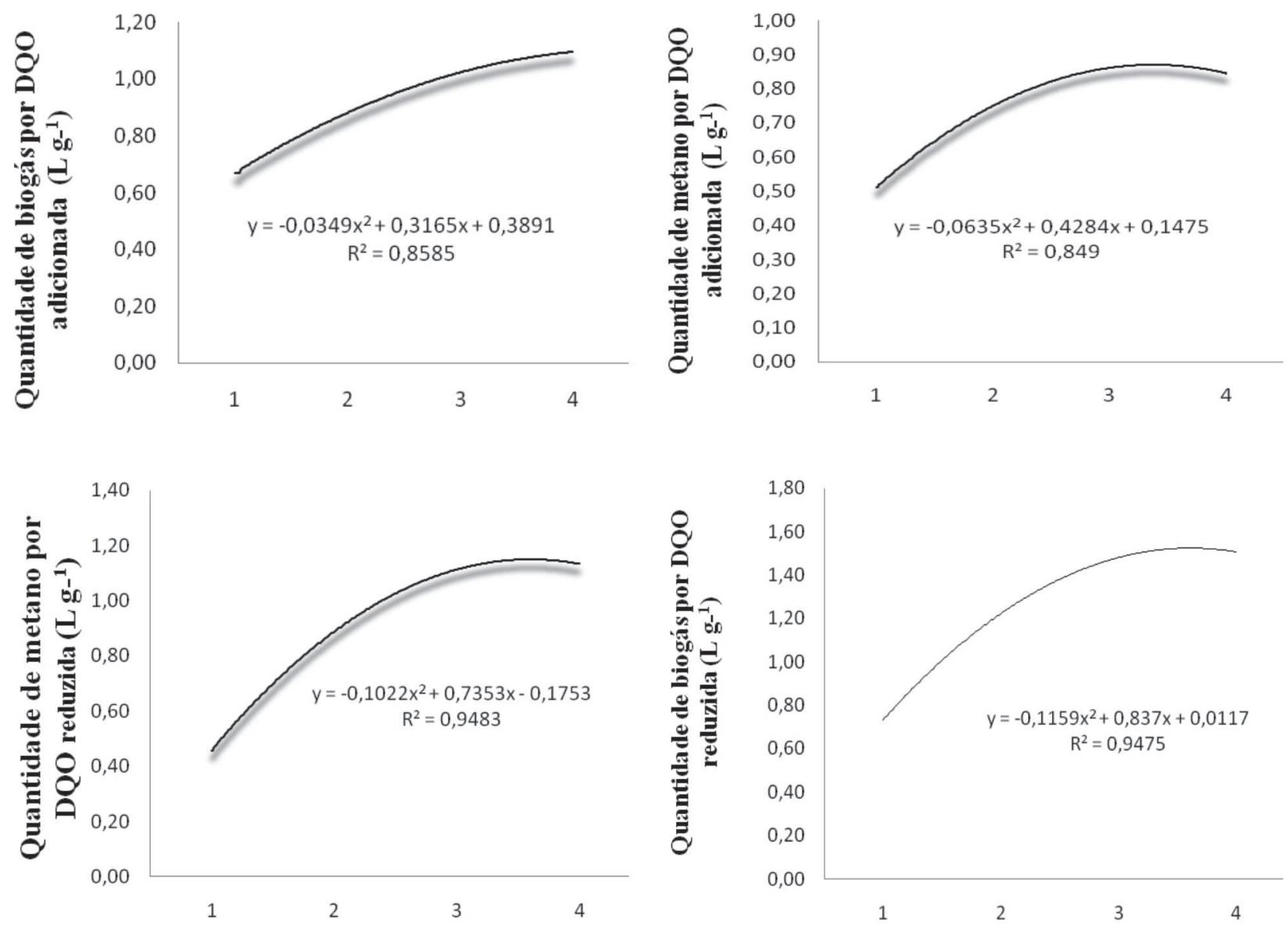

Figura 3. Potenciais de produção de biogás e metano por DQO adicionada (DQOA) e reduzida (DQOR), durante a biodigestão de efluente de abatedouro avícola em função das concentrações de enzimas usadas. 
Os resultados encontrados neste experimento foram semelhantes aos obtidos por Valladão et al. (2007). Os autores relatam que, ao se realizar uma pré-hidrólise no efluente, promoveu-se um aumento na produção de biogás (de 37 para $175 \mathrm{~mL}$, em 4 dias de avaliação), utilizando-se a adição de $0,1 \%$ do peso/volume. A diferença entre os volumes de produção obtidos neste estudo e os compilados por Valladão et al. (2007) provavelmente se deve ao volume dos biodigestores utilizados, sendo que o autores utilizaram recipientes de $100 \mathrm{~mL}$ para realização do ensaio de biodigestão.

Os valores máximos encontrados no presente experimento para a produção diária de biogás $\left(1,9 \mathrm{~L} \mathrm{~d}^{-1}\right.$, o que, considerando-se o volume de carga, representaria $132 \mathrm{~mL}$ $\mathrm{g}_{\text {DQO }} \mathrm{d}^{-1}$ adicionada ao biodigestor) foram superiores aos encontrados por Dors (2006), que obteve produção média de $10 \mathrm{~mL} \mathrm{~g}$ DQo $\mathrm{d}^{-1}$ adicionada ao biodigestor (em biodigestores modelo batelada, com capacidade para 300 $\mathrm{mL}$ de substrato, em fermentação). Possivelmente, a divergência entre os valores possa estar associada à variabilidade das características químicas do resíduo, ao período de retenção dos substratos e, principalmente, à não renovação diária do conteúdo em fermentação para os biodigestores batelada. As percentagens de metano, contidas no biogás, considerando as concentrações de enzimas, foram de 72,$6 ; 78,8 ; 78,9 ; 79,5 \%$, para os níveis de $0 ; 0,5 ; 1,0 ; 1,5 \%$ respectivamente (Tabela 2). Essas concentrações de $\mathrm{CH}_{4}$ encontradas foram superiores às obtidas por Leal et al. (2006), que, ao estudarem os efeitos da hidrólise enzimática sobre tratamento anaeróbio de efluentes de laticínios com alto teor de lipídios, obtiveram valores médios de concentração de $67 \%$.

As produções e os potenciais de produção de biogás, bem como as concentrações de metano e as remoções de DQO, encontrados no experimento, para os diferentes tempos de retenção hidráulica utilizados, estão apresentados na Tabela 3.
Foram observadas remoções significativas, nos valores de DQO, entre os TRHs utilizados, em que o TRH de 21 dias apresentou maiores reduções $(74,4 \%)$ nos teores de DQO, seguido do TRH 14 (71,5\%) e 7 (63,7\%) que apresentaram menor remoção. O melhor desempenho obtido pelo TRH de 21 dias pode estar associado ao maior tempo de exposição, das frações de lenta degradação, aos microorganismos, como é o caso da fração lipídica, principal componente do efluente de abatedouro, que, por apresentar cadeia carbônica mais longa, quando comparada com a das proteínas e dos carboidratos, necessita de maior tempo para sua completa degradação e transformação em produtos menos complexos, como $\mathrm{CH}_{4}, \mathrm{CO}_{2}$ e $\mathrm{H}_{2} \mathrm{O}$.

Os valores verificados neste trabalho foram inferiores aos encontrados por Gannoun et al. (2009) que, ao avaliarem a influência dos diferentes TRH e de concentrações de material orgânico, presentes em efluentes de abatedouro, sobre os processos de biodigestão anaeróbia, obtiveram remoções médias de $90 \%$.

Ogejo \& Li (2010), ao realizarem a biodigestão anaeróbia de efluentes de abatedouro de peru (DQO inicial de $3910 \mathrm{mg} \mathrm{L}^{-1}$ ), utilizando um TRH de 5 dias, obtiveram redução $83,6 \%$ superior às encontradas neste experimento. Essas diferenças, encontradas entre este experimento e os realizados por Gannoun et al. (2009) e Ogejo \& Li (2010), podem estar associadas com a variabilidade das frações que compõem o efluente de abatedouro, uma vez que esta podem apresentar grandes variações entre plantas de abate e, até mesmo, dentro de uma mesma planta.

De acordo com os resultados apresentados na Tabela 3 , nota-se que o TRH de 21 dias proporcionou maior remoção de material orgânico; contudo, os efluentes desses biodigestores não poderiam ser descartados em rios ou demais corpos hídricos naturais, pois, de acordo com a Conselho Estadual de Controle Ambiental de Mato Grosso do Sul (CECA/MS), que obedece, para o lançamento de águas residuárias em corpos hídricos, os limites do art.

Tabela 3. Produções semanais de biogás $\left(\mathrm{L}^{-1}\right)$, teores de metano na composição e potenciais de produção de biogás e metano por $\mathrm{g}^{-1}$ de DQO adicionada (DQOa) e reduzida (DQOr) e \% de remoção de DQO (RDQO) durante a biodigestão de efluente de abatedouro avícola em função dos tempos de retenção hidráulica

\begin{tabular}{lcccr}
\hline \multirow{2}{*}{ Variáveis } & \multicolumn{4}{c}{ Tempos de retenção hidráulica } \\
\cline { 2 - 5 } & $\mathbf{7}$ & $\mathbf{1 4}$ & $\mathbf{2 1}$ & $\mathbf{C V}(\boldsymbol{\%})$ \\
\hline RDQO $(\%)$ & $63,7 \mathrm{c}$ & $71,5 \mathrm{~b}$ & $74,4 \mathrm{a}$ & 4,2 \\
Biogás/DQOa $\left(\mathrm{L} \mathrm{g}^{-1}\right)$ & 0,9 & 0,9 & 0,8 & 37,7 \\
Biogás/DQOr $\left(\mathrm{L} \mathrm{g}^{-1}\right)$ & $1,9 \mathrm{a}$ & $1,0 \mathrm{~b}$ & $0,8 \mathrm{~b}$ & 52,1 \\
$\mathrm{CH}_{4} / \mathrm{DQOa}\left(\mathrm{L} \mathrm{g}^{-1}\right)$ & 0,8 & 0,8 & 0,7 & 52,5 \\
$\mathrm{CH}_{4} / \mathrm{DQOr}\left(\mathrm{L} \mathrm{g}^{-1}\right)$ & $1,4 \mathrm{a}$ & $0,7 \mathrm{~b}$ & $0,6 \mathrm{~b}$ & 35,0 \\
Biogás $\left(\mathrm{L}^{-1}\right)$ & $40,7 \mathrm{a}$ & $18,3 \mathrm{~b}$ & $11,0 \mathrm{c}$ & 23,3 \\
Metano $(\%)$ & 78,5 & 76,6 & 77,4 & 3,7 \\
Metano $\left(\mathrm{L}^{-1}\right)$ & $32,2 \mathrm{a}$ & $14,0 \mathrm{~b}$ & $8,5 \mathrm{c}$ & 12,1 \\
\hline
\end{tabular}

Na linha, letras minúsculas comparam resultados obtidos por níveis de adição de enzima. Médias seguidas de letras distintas diferem entre si, pelo teste de Scott-Knott $(\mathrm{P}<0,05)$.

Rev. Ceres, Viçosa, v. 58, n.6, p. 690-700, nov/dez, 2011 
5 da resolução CONAMA no 20, de 18 de junho de 1986 e ou da resolução, atual, CONAMA 357/05, cujo limite padrão para DQO é de 3 a $5 \mathrm{mg} \mathrm{L}^{-1}$, e considerando-se as percentagens de remoção em função do TRH de 21 dias, a DQO média seria de $638,0 \mathrm{mg} \mathrm{L}^{-1}$. O lançamento do efluente dos biodigestores poderia levar ao comprometimento daqueles corpos hídricos onde fossem descartados. Mesmo assim, isso não impede o reaproveitamento do efluente para a irrigação de culturas como, por exemplo, cana-deaçúcar, milho, sorgo, frutas e madeira em reflorestamentos (Mattos, 2005).

Os resultados apresentados na Tabela 3 demonstram que não houve influência $(\mathrm{P}>0,05)$ dos TRH utilizados, sobre os potenciais de produções de biogás e metano por DQO adicionada. No entanto, houve diferença $(\mathrm{P}<0,05)$ para os potenciais de produção de biogás e metano por DQO removida, sendo que, à medida que se aumentou o tempo de retenção hidráulica, reduziram-se os valores de produção (Figura 4).

As produções de biogás e metano foram maiores quando se utilizou o TRH de 7 dias, seguido dos TRH's de 14 e 21, respectivamente. Possivelmente, esse comportamento esteja associado à maior taxa de renovação de nutrientes, por causa do grande fluxo de resíduo que entra nos biodigestores, quando comparado com a dos demais TRHs utilizados, o que faz com que a renovação do material de fácil degradação seja constante, possibilitando, assim, maior eficiência na reciclagem energética.

Os resultados deste estudo estão de acordo com informações compiladas por Amaral et al. (2004), que atribuíram essas maiores produções, considerando-se TRHs menores, às maiores cargas orgânicas a que esses sistemas são submetidos. Desta forma, associam-se esses resultados ao volume médio diário de carga realizado nos biodigestores, que foram de 3,6, 1,9 e 1,3 L $\mathrm{L}^{1}$, para os TRH's de 7, 14 e 21 dias respectivamente. Mesmo assim, faz-se necessário ressaltar que, como os teores de metano não apresentaram diferenças em função dos TRHs, os resultados $\left(\mathrm{CH}_{4} / \mathrm{DQOr}\right.$ e volume de $\left.\mathrm{CH}_{4}\right)$ apresentaram comportamento semelhantes.

A concentração de metano, obtida para o TRH de 7 dias, foi semelhante à encontrada por Ogejo \& Li (2010), após biodigestão anaeróbia de água residuária de abatedouro de peru, utilizando um TRH de 5 dias (média de $70 \%$ de $\mathrm{CH}_{4}$ ). As concentrações de $\mathrm{CH}_{4}$ e $\mathrm{CO}_{2}$, em função dos tratamentos utilizados, estão de acordo com valores médios preconizados por Souza et al. (2010). De acordo com os autores, os principais constituintes do biogás são o metano (60 - 80\%) e o dióxido de carbono (20 - 40\%).

Os valores de $\mathrm{pH}$ encontrados no experimento, para os diferentes tempos de retenção hidráulica e concentrações de enzimas utilizadas, são apresentados na Tabela 4.

De acordo com os resultados mostrados na Tabela 4, houve diferença $(\mathrm{P}<0,05)$ entre os $\mathrm{pH}$ dos resíduos após os tratamentos realizados. Com o aumento do TRH, houve uma elevação do $\mathrm{pH}$ para níveis mais próximos da neutralidade. Isso pode ter ocorrido pelo fato de o resíduo passar mais tempo dentro do biodigestor, o que possibilita maior consumo dos produtos (ácidos e, ou, compostos intermediários na formação de $\mathrm{CO}_{2} \mathrm{e} \mathrm{CH}_{4}$ ), gerados durante a degradação do material, pelos micro-organismos presentes no ambiente.

Os valores de $\mathrm{pH}$ obtidos, quando relacionados com as diferentes concentrações de enzimas utilizados, demonstram que, conforme se aumentou a concentração de enzimas, promoveu-se maior acidificação do meio. Isso pode ser resultado do possível acúmulo de produtos intermediários (ácidos graxos de cadeia longa), o que leva ao surgimento de eventuais problemas como, por exemplo, a toxicidade aos micro-organismos (acetogênicos e metanogênicos), refletindo-se na taxa de produção de metano (Gannoun et al., 2009) e, portanto, na retirada de

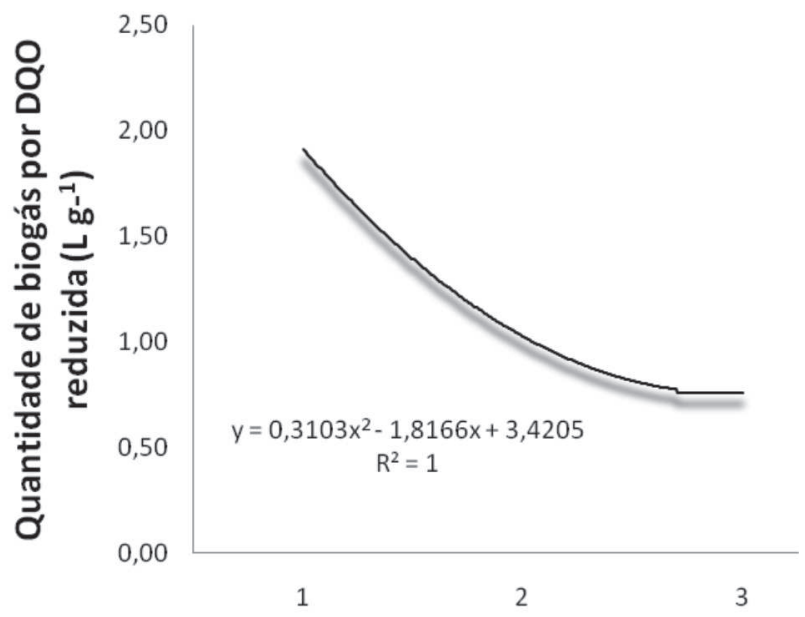

Figura 4. Potenciais de produção de biogás e metano por DQO reduzida (DQOR), durante a biodigestão de efluente de abatedouro avícola em função do tempo de retenção hidráulica usados. 
$\mathrm{H}^{+}$do meio. Porém, os resultados obtidos neste experimento foram semelhantes aos dos de outros autores (Rigo, 2004; Schoenhals, 2006; Gannoun et al., 2009; Ogejo \& Li, 2010) que, ao realizarem a biodigestão anaeróbia de efluentes de abatedouros, obtiveram valores médios que oscilaram entre 6,7 e 7,9.

Não foram verificadas diferenças significativas $(\mathrm{P}>0,05)$ entre os tratamentos, quanto às reduções no NMP de coliformes totais e termotolerantes. Também não foi observada presença de coliformes termotolerantes e totais, em todos os ensaios realizados nos efluentes dos biodigestores. De acordo com Orrico Júnior et al.(2009), esse resultado não está somente vinculado ao processo de biodigestão anaeróbia, mas, também, ao modelo de biodigestor utilizado, visto que o biodigestor tubular semicontínuo caracteriza-se por apresentar elevada produção de ácido na entrada do biodigestor, e, como a ação do pH dá-se logo no início do processo, reduz-se, assim, a população de coliformes no material de entrada.

O biofertilizante obtido a partir da biodigestão anaeróbia de efluente de abatedouro avícola apresenta características microbiológicas adequadas para sua aplicação a culturas como, por exemplo, cana- de- açúcar, milho, sorgo, frutas e madeira em reflorestamentos, pois, de acordo com a Organização Mundial de Saúde (OMS), admitem-se, como concentração permissível para a irrigação dessas culturas, quantidades inferiores a 100 coliformes $100 \mathrm{~mL}^{-1}$ de biofertilizante.

Os resultados encontrados neste trabalho para a eficiência de remoção de coliformes totais e termotolerantes foram semelhantes aos obtidos por Gannoun et al. (2009), que avaliaram diferentes tempos de retenção hidráulica (TRH) e níveis de material orgânico e observaram uma redução média de coliformes totais e termotolerantes de $99,9 \%$.

Os valores de $\mathrm{N}, \mathrm{P}$ e $\mathrm{K}$ encontrados, no experimento, para os diferentes tempos de retenção hidráulica e concentrações de enzimas utilizados, são apresentados na Tabela 5.

De acordo com os dados apresentados na Tabela 5, observa-se que houve influência $(\mathrm{P}<00,5)$ dos TRHs utilizados sobre a concentração dos teores de $\mathrm{N}$ e $\mathrm{P}$, cujos maiores valores foram atribuídos ao TRH de 21 dias (152,6 e 5,8 para $\mathrm{N}$ e $\mathrm{P}$, respectivamente).

Os resultados obtidos neste estudo para $\mathrm{N}$ e $\mathrm{P}$ podem estar associados com a menor taxa de passagem do resíduo pelos biodigestores com TRH de 21 dias, o que levou a uma maior homogeinidade do afluente.

Tabela 4. Valores de pH após a biodigestão da água residuária de abatedouro avícola em função dos tempos de retenção hidráulica e dos níveis de enzimas

\begin{tabular}{|c|c|c|c|c|}
\hline \multirow{2}{*}{ Variáveis } & \multicolumn{4}{|c|}{ Tempos de retenção hidráulica } \\
\hline & 7 & & 14 & 21 \\
\hline $\mathrm{pH}$ & $6,82 \mathrm{c}$ & & $6,96 b$ & $7,04 \mathrm{a}$ \\
\hline \multirow{2}{*}{ Variáveis } & \multicolumn{3}{|c|}{ Níveis de Enzimas } & \\
\hline & $\mathbf{0}$ & $\mathbf{0 , 0 5}$ & $\mathbf{0 , 1 0}$ & 0,15 \\
\hline $\mathrm{pH}$ & $7,03 \mathrm{a}$ & $6,96 \mathrm{~b}$ & $6,89 \mathrm{c}$ & $6,88 \mathrm{c}$ \\
\hline C.V & & & & 1,6 \\
\hline
\end{tabular}

Na linha, letras minúsculas comparam resultados obtidos por níveis de adição de enzima e tempos de retenção hidráulica. Médias seguidas de letras distintas diferem entre si, pelo teste de Scott-Knott $(\mathrm{P}<0,05)$.

Tabela 5 - Teores de N, P e K após a biodigestão anaeróbia do efluente de abatedouro avícola em função dos tempos de retenção hidráulica e dos níveis de enzimas adicionados

\begin{tabular}{|c|c|c|c|c|c|}
\hline \multirow{2}{*}{ Variáveis } & \multicolumn{5}{|c|}{ Tempos de retenção hidráulica } \\
\hline & 7 & & & 21 & C.V \\
\hline $\mathrm{N}$ amoniacal $\left(\mathrm{mg} \mathrm{L}^{-1}\right)$ & $122,0 \mathrm{~b}$ & & & $152,6 \mathrm{a}$ & 13,9 \\
\hline $\mathrm{P}$ total $\left(\mathrm{mg} / \mathrm{L}^{-1}\right)$ & $4,8 b$ & & & $5,8 \mathrm{a}$ & 13,4 \\
\hline $\mathrm{K}\left(\mathrm{mg} / \mathrm{L}^{-1}\right)$ & $69,9 a$ & & & 76,4 & 9,5 \\
\hline \multirow{2}{*}{ Variáveis } & \multicolumn{5}{|c|}{ Níveis de Enzimas } \\
\hline & $\mathbf{0}$ & $\mathbf{0 , 0 5}$ & $\mathbf{0 , 1 0}$ & $\mathbf{0 , 1 5}$ & C.V \\
\hline $\mathrm{N}\left(\mathrm{mg} \mathrm{L}^{-1}\right)$ & 152,8 & 135,8 & 126,6 & 131,1 & 13,9 \\
\hline $\mathrm{P}\left(\mathrm{mg} \mathrm{L}^{-1}\right)$ & 5,1 & 5,4 & 5,1 & 5,1 & 13,4 \\
\hline $\mathrm{K}\left(\mathrm{mg} \mathrm{L}^{-1}\right)$ & 71,2 & 76,5 & 73,0 & 69,7 & 9,5 \\
\hline
\end{tabular}

Na linha, letras minúsculas comparam resultados obtidos por níveis de adição de enzima e tempos de retenção hidráulica. Médias seguidas de letras distintas diferem entre si, pelo teste de Scott-Knott $(\mathrm{P}<0,05)$.

Rev. Ceres, Viçosa, v. 58, n.6, p. 690-700, nov/dez, 2011 
Não foram observadas diferenças significativas para os teores de $\mathrm{K}$ em função dos TRHs. Os resultados da Tabela 5 demonstram que não houve influência $(\mathrm{P}>0,05)$ das concentrações sobre os teores N, P e K.

Ogejo \& Li (2010) obtiveram valores médios de 100, 15 e $41 \mathrm{mg} \mathrm{L}^{-1}$ para N, P e K, respectivamente, ao submeterem efluente de abatedouro de peru à biodigestão anaeróbia, adotando TRH de 5 dias e concentração de ST e DQO de $2.500 \mathrm{mg} \mathrm{L}^{-1}$ e $3.910 \mathrm{mg} \mathrm{L}^{-1}$, respectivamente. As diferenças encontradas entre os resultados deste trabalho e os compilados por esses autores podem estar associadas à composição dos efluentes, principalmente quanto às quantidades de sangue e fragmentos cárneos no resíduo.

De acordo com a legislação CONAMA 357 (2005), o valor padrão estabelecido para descarte de fósforo em ambiente lótico é de $0,1 \mathrm{mg} \mathrm{L}^{-1}$. Dessa forma, não se recomenda o descarte do efluente dos biodigestores diretamente em corpos hídricos, pois isso poderia causar sérios problemas ambientais, como a eutrofização. Contudo, o uso desse efluente em culturas forrageiras mostra-se alternativa interessante, uma vez que a maioria dos solos brasileiros é deficiente desse mineral.

\section{CONCLUSÃO}

O pré-tratamento com a adição de lipase foi eficiente para aumentar a produção de biogás e metano, bem como para levar a aumento na remoção de material orgânico, em biodigestores semicontínuos alimentados com efluente de abatedouro de aves. Contudo, para que haja maior eficiência na reciclagem energética, recomenda-se a utilização de concentração de até $1,0 \mathrm{~g} \mathrm{~L}^{-1}$ de enzima e tempo de retenção hidráulica de 7 dias.

\section{REFERÊNCIAS BIBLIOGRÁFICAS}

Alvares R \& Lidén G (2008) Semi-continuous co-digestion of solid slaughterhouse waste, manure, and fruit and vegetable waste. Renewable Energy, 33:726-734.

Amaral CMC, Amaral LA, Lucas Júnior J, Nascimento AA, Ferreira DS \& Machado MRF (2004) Biodigestão anaeróbia de dejetos de bovinos leiteiros submetidos a diferentes tempos de retenção hidráulica. Ciência Rural, 34:1897-1902.

American public health Association - APHA (1995) Standard methods for examination of water and wastewater. 19th ed., Washington, American Water Works Association. 1134p.

Bataglia OG, Furlani AMC, Teixeira JPF, Furlani PR \& Gallo JR (1983) Métodos de análises químicas de plantas. Campinas, Instituto Agronômico. 48p.

Beux S (2005) Avaliação do tratamento de efluente de abatedouro em digestores anaeróbios de duas fases. Dissertação de Mestrado. Universidade Estadual de Ponta Grossa, Ponta Grossa. 98p.

Caetano L (1985) Proposição de um sistema modificado para quantificação de biogás. Dissertação de Mestrado. Faculdade de Ciências Agronômicas, Universidade Estadual Paulista, Botucatu. $75 \mathrm{p}$.
Camarota MC, Teixeira GA \& Freire DMG (2001) Enzymatic prehydrolysis and anaerobic degradation of wastewaters with high fat contents. Biotechnology Letters, 23:1591-1595.

Chen Y, Cheng JJ \& Creamer KS (2008) Inhibition of anaerobic digestion process: A review. Bioresource Technology, 99:40444064.

Cirne DG, Paloumet X, Björnsson L, Alves MM \& Mattiasson B (2007) Anaerobic digestion of lipid-rich waste-Effects of lipid concentration. Renewable Energy, 32:965-975.

Conselho Nacional do Meio Ambiente - CONAMA (2005) Resolução no 357 de 17 de março de 2005. Classifica as águas doces, salobras e salinas. Diário Oficial da República Federativa do Brasil, Brasília, 18 de março de 2005.

Dors G (2006) Hidrólise enzimática e biodigestão de efluentes da indústria de produtos avícolas. Dissertação de Mestrado. Universidade Federal de Santa Catarina, Florianópolis. 69p.

Gannoun H, Bouallagui H, Okbi A, Sayadi S \& Hamdi M (2009) Mesophilic and thermophilic anaerobic digestion of biologically pretreated abattoir wastewaters in an upflow anaerobic filter. Jornal of Hazardous Materials, 170:263-271.

Johns MR (1995) Developments in wastewater treatment in the meat processing industry: a review. Bioresource Technology, 54:203-216

Leal MCMR, Freire DMG, Cammarota MC \& Sant' Anna Júnior GL (2006) Effect of enzymatic hydrolysis on anaerobic treatment of dairy wastewater. Process Biochemistry, 41:11731178 .

Malavolta E, Boareto AE \& Paulino VT (1989) Micronutrientes, uma visão geral. In: Ferreira ME; Cruz MC (Eds.) Micronutrientes na Agricultura. Piracicaba, POTAFOS/CNPq. $1-33 p$.

Matos AT (2005) Tratamento de resíduos agroindustriais. Curso sobre tratamento de resíduos agroindustriais. Viçosa, Universidade Federal de Viçosa. p27.

Mendes AA, Castro HF, Pereira EB \& Furigo Júnior A (2005) Aplicação de lipases no tratamento de águas residuárias com elevados teores de lipídeos. Química Nova, 28:296-305.

Ogejo JA \& Li L (2010) Enhancing biomethane production from flush dairy manure with turkey processing wastewater. Applied Energy, 87:3171-3177.

Orrico Júnior MOP, Orrico ACA \& Lucas Júnior JL (2009) Biodigestão anaeróbia de dejetos de suínos com e sem separação da fração sólida em diferentes tempos de retenção hidráulica. Engenharia Agrícola, 29:474-482.

Orrico Júnior MOP, Orrico ACA \& Lucas Júnior JL (2010) Influência da relação volumoso: concentrado e do tempo de retenção hidráulica sob a biodigestão anaeróbia de dejetos de bovinos. Engenharia Agrícola, 30:386-394.

Rigo E (2004) Aplicação de Lipaselipases como auxiliar no prétratamento de efluentes de frigoríficos de suínos e bovinos. Dissertação de Mestrado. Universidade Regional integrada do alto Uruguai e das missões, Erechim. 84p.

Rigo E, Rigoni RE, Lodea P, Lodea P, Oliveira D, Freire DMG, Treichel H \& Di Luccio M (2008) Comparison of two lipases in the hydrolysis of oil and grease in wastewater of the swine meat industry. Engineering Chemistry Research, 47:1760-1765.

Rosa DR, Duarte ICS, Saavedra NK, Varesche MB, Zaiat M, Cammarota MC \& Freire MG (2009) Performance and molecular evaluation of an anaerobic system with suspended biomass for treating wastewater with high fat content after enzymatic hydrolysis. Bioresource Technology, 100:6170-6176. 
Salminen E \& Rintala J (2002) Anaerobic digestion of organic solid poultry slaughterhouse waste: a review. Bioresource Technology, 83:13-26.

Schoenhals M (2006) Avaliação da eficiência do processo de flotação aplicado ao tratamento primário de efluentes de abatedouro avícola. Dissertação de Mestrado. Universidade Federal de Santa Catarina, Florianópolis. 87p.

Silva DJ (1981) Análise de alimentos: métodos químicos e biológicos. Viçosa, Editora Universitária. 166p.

Souza O, Federizzi M, Coelho B, Wagner TM \& Wisbeck E (2010) Biodegradação de resíduos lignocelulósicos gerados na bananicultura e sua valorização para a produção de biogás. Revista Brasileira de Engenharia Agrícola e Ambiental, 14:438-443.

União Brasileira de Avicultura - UBA (2011) Relatório anual 2010. p. 21.
SAEG (2000) Sistema de análises estatísticas e genéticas. Versão 8.0. Viçosa, Universidade Federal de Viçosa. 142p.

Valladão ABG, Sartore PE, Freire DMG \& Cammarota MC (2009) Evaluation of different pre-hydrolysis times and enzyme pool concentrations on the biodegradability of poultry slaughterhouse wastewater with a high fat content. Water Science \& Technology, 60:243-249.

Valladão ABG (2005) Pré-hidrólise enzimática aplicada ao tratamento anaeróbio de efluente de abatedouro de aves. Dissertação de Mestrado. Universidade Federal do Rio de Janeiro, Rio de Janeiro. p.79.

Valladão ABG, Freire DMG \& Cammarota MC (2007) Enzymatic pre-hydrolysis applied to the anaerobic treatment of effluents from poultry slaughterhouses. International Biodeterioration \& Biodegradation, 60:219-225 